\title{
Exposição à competição informal e esforço de inovação das empresas industriais brasileiras
}

\author{
Luiz A. Esteves*
}

RESUMO - O objetivo deste artigo foi verificar como a exposição à competição informal pode comprometer o desempenho dos estabelecimentos industriais brasileiros em termos de vendas e emprego. O esforço inovador das empresas sob diferentes graus de exposição à competição informal também foi analisado. Os resultados apresentados neste trabalho sugerem que a existência de estabelecimentos informais pode trazer sérias implicações para as empresas formais, seja em termos de lucratividade e geração de empregos. Finalmente, foi visto que as empresas com alta exposição à competição informal apresentam tecnologia inferior ao de seus competidores formais diretos.

Palavras-chave: Informalidade. Concorrência. Inovação.

\section{INTRODUÇÃo}

No início do ano de 2009, a OCDE (Organização para Cooperação e Desenvolvimento Econômico) organizou um fórum sobre competição (Global Forum Competition), onde delegados representando mais de 100 agências de defesa da concorrência ao redor mundo buscaram aumentar seus conhecimentos sobre o setor informal e suas consequências para a concorrência. A questão chave daquela seção do fórum era: "Deveriam as agências de defesa da concorrência se importar com o setor informal?".

O tema da informalidade tem despertado grande interesse da academia nos últimos anos, porém maior destaque tem sido devotado para o papel da informalidade sobre o mercado de trabalho e sobre as políticas públicas de tributação. No caso do papel da concorrência entre estabelecimentos formais e informais, o tema tem despertado interesse de formuladores de políticas públicas, porém a literatura acadêmica tem fornecido pouca evidência empírica para o caso.

O objetivo deste artigo é verificar como a exposição à competição informal pode comprometer o desempenho dos estabelecimentos industriais brasileiros em termos de vendas e emprego. Deseja-se também analisar o esforço inovador das empresas sob diferentes graus de exposição à competição informal.

\footnotetext{
* Doutor em Economia pela Università degli Studi di Siena. Professor do departamento de economia da Universidade Federal do Paraná (UFPR). Endereço eletrônico: esteves@ufpr.br.
} 
Os resultados das estatísticas descritivas apresentadas ao longo deste trabalho sugerem que uma maior exposição à competição com o setor informal implica em uma menor taxa de crescimento das empresas formais. Verificamos também que as empresas mais expostas à competição informal apresentam maior esforço inovador.

Este artigo é dividido em quatro seções, incluindo a presente introdução. A segunda seção apresenta a base de dados e os resultados das estatísticas descritivas sobre o desempenho de vendas e emprego das empresas formais do setor industrial. A terceira seção apresenta uma análise descritiva das variáveis de esforço inovador das empresas por categoria de exposição à competição informal. A última seção apresenta as considerações finais e conclusões.

\section{COMPETIÇÃO DESLEAL E DESEMPENHO DAS EMPRESAS}

A base de dados utilizada neste teste empírico é o World Bank Investment Climate, Brazil (2003). Esta pesquisa fornece informações individuais de 1.642 empresas industriais brasileiras entrevistadas no ano de 2003, porém as informações disponíveis referem-se ao exercício anterior, $2002^{1}$. O uso de pesos amostrais torna a pesquisa representativa para 17.631 empresas industriais brasileiras. Importante esclarecer que todas as empresas da amostra são formais.

$\mathrm{Na}$ tabela 1 podemos verificar a frequência de empresas por classe de exposição à competição informal:

TABELA 1 - FREQUÊNCIA DE EMPRESAS POR CATEGORIA

\begin{tabular}{l|c|}
\hline \multicolumn{1}{|c|}{ Exposição } & Empresas \\
\hline Nenhum (=0) & 167 \\
Pequeno $(=1)$ & 178 \\
Moderado (=2) & 368 \\
Grande (=3) & 467 \\
Muito severo (=4) & 454 \\
\hline
\end{tabular}

Podemos constatar na tabela 1 e no gráfico 1 que os graus de exposição mais elevados abrigam maiores quantidades de empresas. Apenas $21 \%$ das empresas da amostra apresentam baixa exposição à competição informal, ou seja, pequena ou nenhuma exposição. Esta estatística é de grande relevância no sentido de esclarecer que é um equívoco imaginar

\footnotetext{
${ }^{1}$ Há informação disponível para o triênio 2000-2002 no caso de informações contábeis e patrimoniais das
} firmas. 
que apenas as empresas dos setores comerciais e de serviços são fortemente afetadas pela concorrência desleal com informais.

$\mathrm{Na}$ tabela 2 são apresentadas as estatísticas descritivas sobre pessoal ocupado, taxa de crescimento do pessoal ocupado, vendas e taxa de crescimento de vendas das empresas da amostra para os diferentes grupos de empresas. Um primeiro ponto a ser considerado é que todos os grupos de empresas apresentam médias de log de vendas de log de pessoal ocupado muito similares. Como estas medidas são proxies de tamanho de firma, podemos constatar que o tamanho médio do grupo de empresas mais expostas à concorrência desleal não difere significativamente do tamanho médio do grupo de empresas menos expostas, ou sem qualquer exposição. Este resultado também merece destaque especial, pois uma ideia bastante difundida no pensamento comum é de que grandes empresas seriam menos expostas à competição informal, porém não é isto que verificamos dos dados extraídos desta base.

GRÁFICO 1 - DISTRIBUIÇÃO DE EMPRESAS, GRAU DE EXPOSIÇÃO

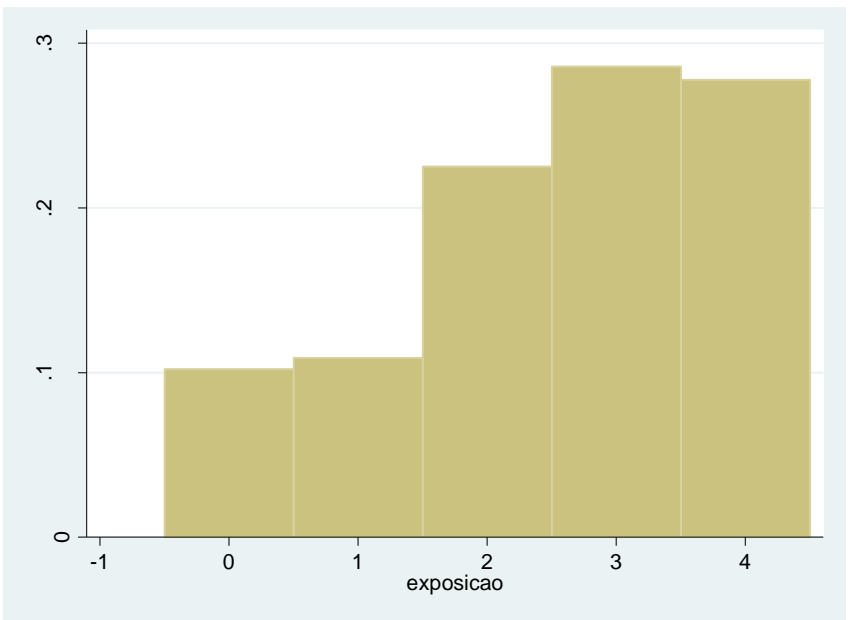

Por outro lado, as taxas médias de crescimento das vendas e do emprego parecem divergir significativamente entre os diferentes grupos de empresas. As empresas com menores graus de exposição à competição informal apresentam taxas de crescimento de vendas e emprego bem superiores aos apresentados pelas empresas com maior exposição. Por exemplo, a taxa média de crescimento do emprego entre 2000 e 2002 foi de $18 \%$ para o conjunto de empresas não expostas à competição informal, enquanto que esta mesma taxa foi de apenas $6 \%$ para o grupo de empresas com grau de exposição muito severo. No caso das taxas médias de crescimento nominal das vendas, estes valores foram de $26 \%$ e 16\%, respectivamente.

Os resultados observados na tabela 2 sugerem que o grau de exposição à competição informal pode constituir um determinante fundamental do crescimento das firmas. No 
entanto, deve estar claro ao leitor que a maior ou menor exposição de uma empresa à competição informal é fruto da sua capacidade em dissuadir a concorrência.

TABELA 2 - ESTATÍTICAS DESCRITIVAS DE DESEMPENHO

\begin{tabular}{|c|c|c|c|c|c|}
\hline Variáveis & $\begin{array}{c}\text { Grau de } \\
\text { exposição } 1 \\
\text { nenhum }\end{array}$ & $\begin{array}{c}\text { Grau de } \\
\text { exposição } 2 \\
\text { pequeno }\end{array}$ & $\begin{array}{c}\text { Grau de } \\
\text { exposição } 3 \\
\text { moderado }\end{array}$ & $\begin{array}{c}\text { Grau de } \\
\text { exposição } 4 \\
\text { grande }\end{array}$ & $\begin{array}{c}\text { Grau de } \\
\text { exposição } 5 \\
\text { muito severo }\end{array}$ \\
\hline Log Pessoal & 3,38 & 3,61 & 3,63 & 3,53 & 3,53 \\
\hline $\begin{array}{l}\text { Ocupado } \\
2000\end{array}$ & $(0,99)$ & $(1,18)$ & $(1,08)$ & $(1,02)$ & $(0,90)$ \\
\hline Log Pessoal & 3,56 & 3,71 & 3,63 & 3,60 & 3,59 \\
\hline $\begin{array}{l}\text { Ocupado } \\
2002\end{array}$ & $(0,96)$ & $(1,12)$ & $(1,08)$ & $(0,99)$ & $(0,87)$ \\
\hline Crescimento & 0,18 & 0,10 & 0,006 & 0,07 & 0,06 \\
\hline $\begin{array}{l}\text { Pessoal } \\
2000-2002\end{array}$ & $(0,42)$ & $(0,34)$ & $(0,39)$ & $(0,35)$ & $(0,41)$ \\
\hline $\begin{array}{l}\text { Log das } \\
\text { Vendas }\end{array}$ & $\begin{array}{l}13,77 \\
(1,80)\end{array}$ & $\begin{array}{l}14,12 \\
(1,94)\end{array}$ & $\begin{array}{l}13,93 \\
(1,83)\end{array}$ & $\begin{array}{l}13,75 \\
(1,79)\end{array}$ & $\begin{array}{l}13,82 \\
(1,56)\end{array}$ \\
\hline $2000(\mathrm{R} \$)$ & & & & & \\
\hline $\begin{array}{l}\text { Log das } \\
\text { Vendas }\end{array}$ & $\begin{array}{l}14,03 \\
(1,77)\end{array}$ & $\begin{array}{l}14,32 \\
(2,03)\end{array}$ & $\begin{array}{l}14,10 \\
(1,84)\end{array}$ & $\begin{array}{l}13,91 \\
(1,81)\end{array}$ & $\begin{array}{l}13,98 \\
(1,60)\end{array}$ \\
\hline $2002(\mathrm{R} \$)$ & & & & & \\
\hline Crescimento & 0,26 & 0,20 & 0,17 & 0,16 & 0,16 \\
\hline $\begin{array}{l}\text { Vendas 2000- } \\
2002\end{array}$ & $(0,58)$ & $(0,50)$ & $(0,46)$ & $(0,53)$ & $(0,48)$ \\
\hline
\end{tabular}

NOTAS: (1) Desvio-padrão entre parênteses; (2) Vendas em valores nominais.

Em termos de políticas públicas, parece que a questão levantada no início 2009 pela

OCDE (Organização para Cooperação e Desenvolvimento Econômico) merece maior atenção: "Deveriam as agências de defesa da concorrência se importar com o setor informal?". Os resultados apresentados nesta seção, embora não sejam definitivos e demandem análises muito mais rigorosas, sugerem que a existência de estabelecimentos informais possa trazer sérias implicações para as empresas formais, seja em termos de lucratividade e geração de empregos.

\section{COMPETIÇÃO DESLEAL E ESFORÇO DE INOVAÇÃO}

O objetivo desta seção é verificar qual o esforço inovador despendido por diferentes grupos de empresas, classificados conforme sua exposição à competição informal. Embora esta seção se limite a uma simples análise comparativa de médias, sem qualquer pretensão de estabelecer causa e efeito das variáveis a serem analisadas, cabe introduzir uma breve discussão teórica sobre a relação entre concorrência e inovação tecnológica.

Schumpeter foi, indubitavelmente, o autor que melhor expôs a relação entre inovação tecnológica e concorrência capitalista. Para este autor, a inovação tecnológica exerce papel fundamental para a economia capitalista, pois é somente através dela que os capitalistas poderiam obter lucros extraordinários em um ambiente competitivo. A ideia é que a 
concorrência entre as empresas levaria as mesmas a operarem com lucros nulos e apenas o desenvolvimento de inovações tecnológicas poderia fazer com que as empresas auferissem, temporariamente, ganhos de monopólio.

Nestes termos, uma hipótese a ser considerada é que as empresas mais expostas à competição deveriam apresentar maior esforço para desenvolvimento de inovações tecnológicas. Neste trabalho buscou-se selecionar da base de dados um conjunto de variáveis que capturassem o esforço inovador das empresas. Estas variáveis são descritas na tabela 3:

TABELA 3 - LISTA DE VARIÁVEIS

\begin{tabular}{l|r|}
\hline \multicolumn{1}{|c|}{ Variável } & Descrição \\
\hline Inova Produto & $\begin{array}{r}\text { Variável dummy: valor igual a um se a empresa desenvolveu inovação de } \\
\text { produto entre os anos de } 2000 \text { e 2002; valor igual a zero caso contrário; } \\
\text { Variável dummy: valor igual a um se a empresa melhorou produtos já } \\
\text { Melhora Produto }\end{array}$ \\
$\begin{array}{l}\text { Cexistentes entre os anos de } 2000 \text { e 2002; valor igual a zero caso contrário; } \\
\text { A variável assume três valores: valor igual a zero caso a empresa não disponha } \\
\text { de nenhuma certificação; valor igual a um caso a empresa esteja em processo } \\
\text { de certificação; valor igual a dois caso a empresa já disponha de certificação; } \\
\text { Variável dummy: valor igual a um se a empresa disponibilizou treinamento } \\
\text { interno a seus funcionários entre os anos de } 2000 \text { e 2002; valor igual a zero } \\
\text { Treinamento Interno contrário; } \\
\text { Treinamento Externo } \\
\text { Variável dummy: valor igual a um se a empresa disponibilizou treinamento } \\
\text { externo a seus funcionários entre os anos de 2000 e 2002; valor igual a zero } \\
\text { caso contrário; } \\
\text { A variável assume três valores: valor igual a zero caso a tecnologia da empresa } \\
\text { seja menos avançada que dos concorrentes; valor igual a um caso a empresa } \\
\text { disponha de tecnologia similar ao de seus concorrentes; valor igual a dois caso } \\
\text { a empresa disponha de tecnologia superior ao de seus concorrentes; }\end{array}$ \\
\hline
\end{tabular}

$\mathrm{Na}$ tabela 4 são apresentados os valores médios das variáveis de esforço de inovação tecnológica das firmas. Novamente, estas estatísticas descritivas são obtidas para vários grupos de empresas, classificadas conforme seu grau de exposição à competição informal.

TABELA 4 - ESTATÍSTICAS DESCRITIVAS DE ESFORCYO INOVADOR

\begin{tabular}{l|r|r|r|r|r}
\hline Variáveis & $\begin{array}{c}\text { Grau de } \\
\text { exposição 1 } \\
\text { Nenhum }\end{array}$ & $\begin{array}{c}\text { Grau de } \\
\text { exposição 2 } \\
\text { Pequeno }\end{array}$ & $\begin{array}{c}\text { Grau de } \\
\text { exposição 3 } \\
\text { Moderado }\end{array}$ & $\begin{array}{c}\text { Grau de } \\
\text { exposição 4 } \\
\text { Grande }\end{array}$ & $\begin{array}{c}\text { Grau de } \\
\text { exposição 5 } \\
\text { Muito severo }\end{array}$ \\
\hline Inova & 0,57 & 0,67 & 0,66 & 0,65 & 0,68 \\
Produto & $(0,49)$ & $(0,47)$ & $(0,47)$ & $(0,47)$ & $(0,46)$ \\
Melhora & 0,87 & 0,93 & 0,96 & 0,94 & 0,95 \\
Produto & $(0,33)$ & $(0,24)$ & $(0,19)$ & $(0,23)$ & $(0,21)$ \\
Certificação & 0,24 & 0,35 & 0,30 & 0,28 & 0,29 \\
Treinamento & $(0,62)$ & $(0,74)$ & $(0,68)$ & $(0,67)$ & $(0,69)$ \\
Interno & 0,46 & 0,50 & 0,48 & 0,47 & 0,45 \\
Treinamento & $(0,50)$ & $(0,50)$ & $(0,50)$ & $(0,50)$ & $(0,49)$ \\
Externo & 0,21 & 0,35 & 0,36 & 0,35 & 0,37 \\
Grau & $(0,55)$ & $(0,48)$ & $(0,48)$ & $(0,47)$ & $(0,48)$ \\
tecnológico & 1,13 & 0,97 & 1,04 & 1,03 & 0,98 \\
NOTAS: & $(0,55)$ & $(0,61)$ & $(0,60)$ & $(0,64)$ & $(0,60)$ \\
\hline
\end{tabular}

NOTAS: (1) Desvio-padrão entre parênteses.

Em primeiro lugar, pode-se verificar claramente que as empresas mais expostas à competição informal apresentam maior esforço inovador. Podemos verificar que do grupo de 
empresas sem qualquer exposição à competição desleal, o percentual de empresas inovadoras de produto é de $57 \%$, enquanto que no grupo de empresas com grau severo de exposição o percentual é de $68 \%$.

Quando indagadas sobre a melhoria de produtos já existentes, $87 \%$ das empresas com nenhuma exposição à competição informal implementaram melhorias, enquanto que 95\% das empresas com grau severo de exposição implementaram melhorias em seus produtos. Este diferencial de esforço inovador é também verificado no caso das certificações: $24 \%$ das empresas sem exposição dispõem de certificação, enquanto este percentual é de $29 \%$ das empresas com exposição muito severa.

No que diz respeito ao treinamento da mão de obra, verificamos que todos os grupos apresentam médias similares no quesito treinamentos internos. $O$ mesmo não é verificado quando consideramos a atividade de treinamento externo: $21 \%$ das empresas sem qualquer exposição à competição informal declararam treinar externamente seus funcionários, enquanto que este percentual é de $37 \%$ das empresas com grau muito severo de exposição.

Um ponto de destaque nesta análise são os resultados da variável grau tecnológico. Nesta variável as empresas eram indagadas sobre sua situação tecnológica frente à de seus concorrentes diretos, ou seja, o empresário deveria responder se seu grau tecnológico era inferior, similar ou superior ao de seus competidores.

Podemos observar das estatísticas da tabela 4 que as empresas sem qualquer exposição aos competidores informais apresentam, em média, tecnologia superior (média acima de 1,00$)$ a de seus concorrentes diretos. Por outro lado, as empresas que constituem o grupo de exposição muito severa apresentam, em média, tecnologia inferior (média abaixo de $1,00)$ a de seus competidores diretos.

Verificamos assim que as empresas com exposição nula à competição informal apresentam tecnologia superior ao de seus competidores diretos, porém seu esforço inovador é inferior ao do grupo de empresas com exposição severa à informalidade. Já estas últimas, que apresentam tecnologia não superior a de seus concorrentes, despendem maior esforço inovador.

\section{CONSIDERAÇÕES FINAIS}

O objetivo deste trabalho foi verificar como a exposição à competição informal pode comprometer o desempenho das empresas formais em termos de vendas e emprego. $\mathrm{O}$ 
esforço inovador das empresas sob diferentes graus de exposição à competição informal também foi analisado ao longo deste trabalho.

Os resultados apresentados neste trabalho sugerem que a existência de estabelecimentos informais pode trazer sérias implicações para as empresas formais, seja em termos de lucratividade e geração de empregos. Cabe esclarecer que estes resultados não são conclusivos e demandam maior investigação empírica, inclusive com utilização de métodos estatísticos e econométricos alternativos.

Finalmente, foi visto que as empresas com exposição nula à competição informal apresentam tecnologia superior ao de seus competidores diretos, porém seu esforço inovador é inferior ao do grupo de empresas com exposição severa à informalidade. Já estas últimas, que apresentam tecnologia não superior a de seus concorrentes, despendem maior esforço inovador. Este resultado sugere a existência de dinâmicas de mercado compostas de empresas líderes e seguidoras engajadas na redução de seu "gap tecnológico". Todavia, enquanto tais empresas seguidoras tentarem lidar com o problema de redução de defasagem tecnológica frente às líderes de mercado, estas empresas serão ainda fortemente expostas à competição com concorrentes informais.

\section{REFERÊNCIAS}

BENNETT, JOHN. Informal firms in developing countries, UNU-MERIT Research Papers nr. 2009/19.

SCHUMPETER, J. A. Teoria do desenvolvimento econômico. São Paulo: Abril Cultural. (Série Os economistas).

SCHUMPETER, J. Capitalism, socialism and democracy. Londres: GeorgeAllen \& Unwin 
